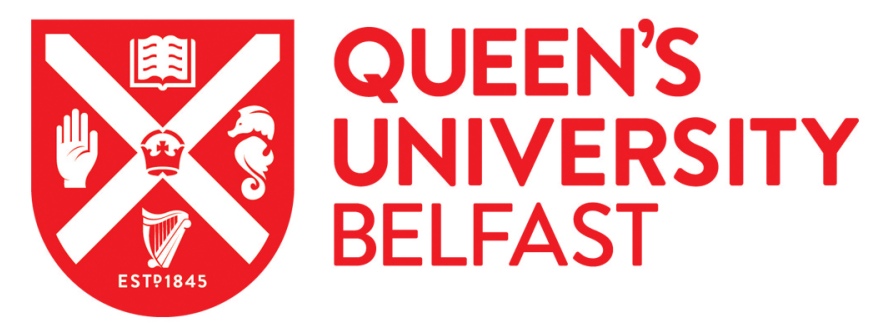

\title{
Receptivity to dating and marriage across the religious divide in Northern Ireland: The role of intergroup contact.
}

Paterson, J. L., Turner, R. N., \& Hodson, G. (2019). Receptivity to dating and marriage across the religious divide in Northern Ireland: The role of intergroup contact. Journal of Applied Social Psychology, 49(9). https://doi.org/10.1111/jasp.12617

Published in:

Journal of Applied Social Psychology

Document Version:

Peer reviewed version

Queen's University Belfast - Research Portal:

Link to publication record in Queen's University Belfast Research Portal

Publisher rights

Copyright 2019 Wiley. This work is made available online in accordance with the publisher's policies. Please refer to any applicable terms of use of the publisher.

\section{General rights}

Copyright for the publications made accessible via the Queen's University Belfast Research Portal is retained by the author(s) and / or other copyright owners and it is a condition of accessing these publications that users recognise and abide by the legal requirements associated with these rights.

Take down policy

The Research Portal is Queen's institutional repository that provides access to Queen's research output. Every effort has been made to ensure that content in the Research Portal does not infringe any person's rights, or applicable UK laws. If you discover content in the Research Portal that you believe breaches copyright or violates any law, please contact openaccess@qub.ac.uk. 
Receptivity to dating and marriage across the religious divide in Northern Ireland: The role of intergroup contact

\author{
Jenny L. Paterson ${ }^{(1)}$, Rhiannon N. Turner ${ }^{(2)}$, and Gordon Hodson ${ }^{(3)}$ \\ ${ }^{(1)}$ Teesside University, UK ${ }^{(2)}$ Queen's University Belfast, UK ${ }^{(3)}$ Brock University, Canada
}

Running head: Receptivity to intergroup dating and marriage

Word count: 5738 excluding abstract, figures and references.

Correspondence concerning this article should be addressed to Jenny Paterson, Department of Psychology, Northumbria University, Newcastle upon Tyne, NE1 8ST, UK. Email: jenny.paterson@northumbria.ac.uk. 


\begin{abstract}
Intergroup contact has long been recognised as an important factor in promoting positive intergroup attitudes. However, in operationalising intergroup attitudes, previous studies have rarely investigated attitudes towards one of the most intimate forms of contact, romantic relationships. In this study $(N=176)$, we expand the intergroup contact literature to examine the association between intergroup contact and, arguably, a litmus test of intergroup attitudes: receptivity to intergroup romance. We do so in Northern Ireland, a context that is historically and presently characterised by sectarian division and tension between Catholics and Protestants. Our findings reveal that intergroup contact is positively associated with receptivity to both dating and marrying an outgroup member. These associations are mediated by ingroup norms towards outgroup romances. General outgroup attitudes were also found to be positively associated with contact but, in contrast to romantic attitudes, this association was shown, for the first time, to be simultaneously mediated by ingroup norms, anxiety, empathy, and trust. In addition, strength of ingroup identification played a moderating role, with a stronger positive relationship between contact and both romantic and general outgroup attitudes among higher identifiers. The findings highlight the importance of examining attitudes towards intergroup romantic relationships, as well as understanding the different mediating and moderating mechanisms which may account for how contact influences general attitudes and romantic attitudes. In the wake of the UK vote to leave the European Union, they also serve as an important reminder of how intergroup contact can be effective in promoting peace in Northern Ireland.
\end{abstract}

Keywords: Intergroup contact; outgroup attitudes; intergroup romantic relationships; Northern Ireland; ingroup norms; ingroup identification; Brexit. 
Receptivity to dating and marriage across the religious divide in Northern Ireland:

The role of intergroup contact

Between 1969 and 1998, over 3600 people were killed in 'the Troubles' between Catholics and Protestants in Northern Ireland. While the signing of the Good Friday/Belfast Agreement in 1998 signalled the end of large-scale violence, two decades on sectarian segregation and tensions persist between the two communities (Hewstone \& Hughes, 2015). Adding to this tense undercurrent, the United Kingdom recently voted to leave the European Union (also known as 'Brexit'). As voting patterns within Northern Ireland are thought to have mirrored sectarian lines, with unionists reflecting a British identity by voting Leave and nationalists reflecting an Irish identity by voting Remain (Gormley-Heenan \& Aughey, 2017), Brexit has re-emphasised, and even reignited, divisions and tensions.

Under these circumstances, it is especially important to understand how and through what mechanisms intergroup contact can promote positive intergroup relations in the region (e.g., Allport, 1954; Pettigrew \& Tropp, 2006). Previous research has identified the benefits of cross-community contact in promoting positive intergroup attitudes in Northern Ireland (Paolini, Hewstone, Cairns, \& Voci, 2004; Tausch, Tam, Hewstone, Kenworthy, \& Cairns, 2007; Turner, Tam, Hewstone, Kenworthy, \& Cairns, 2013). The current research makes an important extension to this literature by assessing receptiveness to a unique, but often overlooked, form of intergroup contact: cross-group romantic relationships. These relationships are particularly important because Catholic-Protestant romances are largely stigmatised and are relatively rare (Leonard, 2009), yet have the potential to improve intergroup relations by transgressing and transforming group boundaries (Paterson, Turner, \& Conner, 2015). As such, we seek to explore how, and through what mechanisms, positive intergroup contact, including previous romantic relationships, influences receptiveness to these intimate relationships. Furthermore, recognising that positive contact may be 
particularly beneficial for people who highly identify with their group (Hodson, Harry, \& Mitchell, 2009; see also Kteily, Hodson, Dhont, \& Ho, 2019), we also test the moderating role of strength of group identification. In doing so, we highlight the utility of examining attitudes towards distinctly intimate forms of cross-group contact, while also providing a timely investigation into a historically precarious context currently enduring yet another threat to intergroup peace.

\section{Intergroup contact in Northern Ireland}

From a theoretical perspective, intergroup contact promotes positive intergroup attitudes for a variety of reasons (Pettigrew, 1998). Contact helps to reduce uncertainty and, therefore, intergroup anxiety about the outgroup (Stephan \& Stephan, 1985). It helps to foster understanding and ties between groups which increases outgroup empathy (Batson et al., 1997). When the contact is pleasant, individuals learn that they can trust the outgroup (Miller, 2002). Furthermore, as individuals often project their own intergroup experiences and related biases onto other ingroup members (MacInnis \& Hodson, 2013), when individuals experience positive contact they assume that other ingroup members feel more positively towards the outgroup as well, thus changing their perceived ingroup norms about intergroup contact (Ata, Bastian, \& Lusher, 2009).

Acknowledging that Northern Ireland represents a somewhat fitting context in which to examine the effects - and processes - of intergroup contact, intergroup theorists have long been interested in the relationship between Catholics and Protestants in the region (e.g., Tajfel, 1970). As such, the context has provided a wealth of knowledge about the positive consequences of contact for intergroup relations, and how contact has these benefits. In line with the theoretical approach, empirical research has shown the positive impacts of contact in Northern Ireland to be mediated by reduced anxiety about intergroup contact (Paolini et al., 2004; Turner et al., 2013), increased trust between Protestants and Catholics (Tam, 
Hewstone, Kenworthy, \& Cairns, 2009), increased empathy for the outgroup (Turner et al., 2013), and perceptions of more tolerant ingroup norms towards sectarian contact (McKeown \& Taylor, 2018)

Although understanding how contact influences attitudes is important, it is also imperative to know who benefits from intergroup contact. In exploring the moderators of the contact-prejudice relationship, researchers have found strength of ingroup identification to play a significant role in intergroup contact (Hodson et al., 2009; Kteily et al., 2019). In general, people who are highly identified with their group show the greatest positive change in their outgroup attitudes as a consequence of intergroup contact. This finding is especially promising as these high identifiers are more likely to avoid intergroup contact and be more prejudiced in the first place, and so are, arguably, the most in need of contact (Hodson et al., 2009). Yet research conducted with regard to identification in Northern Ireland has been mixed. Tausch and colleagues (2007), for example, divided participants into high and low group identifiers and found that, consistent with previous research, contact improved intergroup attitudes via reduced perceptions of symbolic threat, but only for those who were highly identified with their group. However, they also found that, for low identifiers only, contact improved attitudes by reducing anxiety. Such discrepancies in the literature, necessitates further exploration of how strength of ingroup identification influences the impacts of contact in Northern Ireland.

\section{Romantic attitudes as an indicator of intergroup relations}

To measure the impact of cross-community contact in Northern Ireland, previous researchers have examined a range of outcomes including general outgroup attitudes (Tausch et al., 2007) and behaviours towards the outgroup (McKeown \& Taylor, 2018). We add to this literature by examining how positive contact between Catholics and Protestants is associated with receptiveness to cross-group romantic relationships, an indicator of social 
distance that is often overlooked in the intergroup contact literature yet is an insightful barometer of intergroup relations (Bogardus, 1967; Joyner \& Kao, 2005). Specifically, the (un)willingness to affiliate and interact with outgroup members at a more intimate level can be independent of overtly negative attitudes (Ata et al., 2009; Williams \& Eberhardt, 2008). Therefore, assessing the receptivity to cross-group romantic relationships, as well as intergroup attitudes in general, provides a much more nuanced understanding of intergroup relations in the region. Interest in these relationships goes beyond a toleration or acceptance of the outgroup, it infers a willingness to integrate with the outgroup on a much more intimate level - a level which has the potential to blur group boundaries through social and even familial ties (Uskul, Lalonde, \& Cheng, 2007). Furthermore, the consequences of actually being in a cross-group romantic relationship in Northern Ireland have been shown to be largely positive for intergroup attitudes and behaviours (Lloyd \& Robinson, 2011), and so a deeper understanding of when and why people choose to enter into such relationships is needed.

Extrapolating from the literature on general outgroup attitudes, one could assume that receptiveness to cross-group romantic relationships, like general attitudes, is positively related to intergroup contact, mediated by anxiety, empathy, trust, and norms in the Northern Ireland context (McKeown \& Taylor, 2018; Paolini et al., 2004; Tam et al., 2009; Turner et al., 2013). For example, having previous positive contact is likely to make individuals feel less anxious about future intergroup contact (Stephan \& Stephan, 1985), facilitating smoother interactions between individuals (Plant \& Devine, 2003). It is therefore feasible that these less awkward cross-group interactions can improve attitudes towards forming closer relationships with outgroup members, including potential romantic partners. In addition, being able to empathise (Cramer \& Jowett, 2010) and trust (Rempel, Holmes, \& Zanna, 1985) individuals is important for the initiation and development of romantic relationships in 
general, and so it is possible that intergroup contact, via these mechanisms, may help develop emotional and, perhaps even, romantic bonds with outgroup members. Lastly, romantic relationships fare better if individuals perceive support from their family and friends for those relationships (Sprecher \& Felmlee, 1992). When individuals have contact with outgroup members, they often project their experiences onto fellow group members (MacInnis \& Hodson, 2013). Thus, when the experiences are positive, individuals are likely to infer that other ingroup members accept and endorse intergroup contact to the same extent that they do. This, then, suggests that intergroup contact can change perceived ingroup norms towards further future contact, including romantic contact, paving the way for more intimate crossgroup relations to form.

While such hypotheses are reasonable, there is an important distinction between general outgroup attitudes and attitudes towards cross-group romances. Due to their potential to merge familial and community identities, cross-group romantic relationships, particularly more serious relationships such as marriage, may be viewed as more threatening and so are considered a substantial norm violation and face much greater disapproval from parents and peers than other forms of contact (Uskul et al., 2007). For example, although being friends with an outgroup member may be tolerated to a degree, dating an outgroup member may encounter sharp criticism from ingroup members, and intergroup marriage may be deemed unacceptable and, indeed, out of the question (Leonard, 2009). Thus, out of all the potential mechanisms by which contact influences attitudes, it is likely that perceived norms about cross-group romantic relations is an especially important mediator between intergroup contact and receptiveness to cross-group romantic relationships (see also Paterson et al., 2015).

Relatedly, although one may assume that individuals who enter into cross-group romantic relationships have the most positive intergroup attitudes (Bogardus, 1967), the 
disapproval that cross-group couples encounter may actually impact their general intergroup attitudes. For example, although couples are likely to initially hold positive intergroup attitudes to engage in romantic relationships with outgroup members, the disapproval they receive from both their ingroup and outgroup (Leonard, 2009; Paterson et al., 2015; Uskul et al., 2007) may negate the positive intergroup attitudes they previously held. So, although partners may hold specific positive attitudes regarding their romantic partners and their intimate cross-group relationships, bearing the brunt of criticism from other group members may limit the generalisability of those positive attitudes. Thus, in a seeming paradox, receptivity to romantic relationships may indicate extremely positive intergroup attitudes (Ata et al., 2009; Bogardus, 1967), but actually being in a cross-group romantic relationship may hamper those initial positive attitudes. Due to this possibility, it is important to control for individuals' previous romantic contact when investigating the impacts of positive general contact on intergroup attitudes.

In addition to understanding the mediators and covariates of the contact-attitude link, it is important to explore potential moderators of the association. Related research into crossgroup relationships elsewhere has shown that individuals high in social dominance orientation (those who endorse group hierarchies) are more likely to oppose intimate crossgroup relationships, including interracial marriage and trans-racial adoption in the US and Canada (Fang, Sidanius, \& Pratto, 1998; Lalonde, Giguère, Fontaine, \& Smith, 2007). Since this orientation is positively linked to ingroup identification (Levin \& Sidanius, 1999), it is likely that those more highly identified with their ingroup will be less accepting of crossgroup intimate relationships. Nevertheless, drawing from the broader intergroup contact literature, it seems that individuals who are highly identified with their group are most likely to benefit from intergroup contact (Hodson et al., 2009). Thus, taken together, this research suggests that individuals highly identified with their group will be less receptive to cross- 
group relationships but their attitudes are more likely to be positively changed by intergroup contact.

In this study we examined the relation between positive intergroup contact and intergroup attitudes of young Catholic and Protestant adults in Northern Ireland, a demographic who are most likely to be entering, or considering entering, into serious intimate relationships. In doing so, we make two important contributions to the literature which can help to increase understanding, and potentially alleviate, existing intergroup tensions. First, we are the first to simultaneously examine the mediational roles of trust, empathy, anxiety and cross-group relationship norms in the relation between contact and attitudes. This is important because it allows us to test the relative strength of the proposed mediators, thereby indicating whether the variables are significant mediators, independent of the effects of the other variables. Second, we go beyond measuring the traditional general outgroup attitudes to examine receptiveness towards cross-group dating and marriage - relationships which are the litmus test of intergroup relations (Kalmijn, 1998). Drawing from the previous literature outlined above, we made the following hypotheses with regard to general positive contact, controlling for previous romantic contact:

H1: Intergroup contact will positively predict general outgroup attitudes, a relation simultaneously mediated by anxiety, empathy, trust, and ingroup dating norms. H2: Intergroup contact will also positively predict receptiveness to cross-group romantic relationships (dating and marriage), with ingroup norms about cross-group romance expected to play the strongest mediation role.

H3: There will be evidence of moderated-mediation in which relations between contact and the proposed mediators will be stronger for those more strongly identified with their group. 


\section{Method}

\section{Participants}

Two hundred and seventy-two students were recruited from Queen’s University Belfast via social media and email lists, and via the Psychology Undergraduate Research Pool. Participants were either entered into a cash prize draw of $£ 50$ or received course credit for taking part in the online cross-sectional study on Qualtrics. Only those who identified as Catholic $(n=106)$ or Protestant $(n=70)$ were included in the analyses. These 176 participants (151 F, 24M, 1 not disclosed) were predominantly White $(n=173)$, with three participants identifying as mixed race. The average age of participants was 21 years old (SD $=5.86)$.

\section{Measures}

Following the demographic questions, participants were directed to measures that were relevant to their community (Catholic or Protestant). All questions for the two groups were the same, but the target group changed depending on which community the participant belonged to (Catholics were asked about the Protestant outgroup and vice versa).

Positive contact with the outgroup was assessed using three items on a 1 (Strongly disagree) to 7 (Strongly agree) scale (Tam et al., 2009): "In the past, my experiences with people from the [outgroup] community have been pleasant", "Over the course of my life, I have had many friends from the [outgroup] community", and "I have had many positive experiences with people from the [outgroup] community" $(\alpha=.65)$.

Previous outgroup romantic relationships was assessed with one item, "How many romantic relationships lasting a month or more have you had with someone who is from the [outgroup] community?" with responses being $1=$ None, $2=$ One, $3=$ Two, $4=$ Three to five; 5 = More than five. This variable was included to serve as a potential covariate. 
Perceived ingroup dating norms was measured on a 9-point scale $(1=$ very negative to $9=$ very positive) using two items, adapted from the ingroup norm used by Turner, Hewstone, Voci, and Vonofakou (2008): "How do you think your parents would feel about you dating someone who is from the [outgroup] community?" and "How do you think your friends would feel about you dating someone who is from the [outgroup] community?" ( $r=$ $.65)$.

Intergroup anxiety was measured with four items adapted from Stephan and Stephan (1985), for example, "I would feel uncomfortable when interacting with someone from the [outgroup] community" $(\alpha=.88)$.

Outgroup empathy was measured on a 7 -point scale $(1=$ strongly disagree to $7=$ strongly agree) with five items from Tam et al. (2009) using the stem "When thinking about people from the [outgroup] community, to what extent do you feel..." "compassionate", "sympathetic", "soft-hearted", "tender", and "warm" $(\alpha=.95)$.

Intergroup trust was assessed using the seven items from Tam et al.'s (2009) study on a 7-point scale and included items such as "I can trust them if they say they want peace", $\alpha=$ 83.

Single items were used to measure personal likelihood of outgroup dating ("Everything else being equal, how likely is it that you would date someone who is from the [outgroup] community?": 1 = Very unlikely to 9 = Very likely) and appropriateness of outgroup marriage partner ("Everything else being equal, how appropriate a marriage partner would you consider someone who is from the [outgroup] community?": 1 = Not at all appropriate to $9=$ Very appropriate). Positive general outgroup attitude was measured using a feeling thermometer in which participants rate how they feel towards the outgroup on a $0=$ cold to $100=$ warm scale (Haddock, Zanna, \& Esses, 1993). 
Strength of group identification was measured with three items on a 7-point scale adapted from Levin et al. (2007): "How important is your religion to your identity?", "How often do you think of yourself as a member of your religious group?", and "How close do you feel to other members of your religious group?", $\alpha=.90$.

\section{Results}

Table 1 presents the descriptive statistics and correlations of the variables. Providing initial support for the hypotheses, controlling for previous romantic outgroup contact, positive contact was positively associated with a positive general attitude (H1), personal likelihood of outgroup dating and appropriateness of outgroup marriage partner (H2). Furthermore, positive contact was positively related to norms, empathy and trust, and negatively with anxiety $(p<.01)$. Norms, empathy and trust were also positively correlated with all criteria variables (positive general attitude, dating, marriage), while anxiety was negatively correlated with the criteria variables $(p s<.01)$

\section{Mediational analyses}

We next tested a path model with observed variables using Mplus (Muthén \& Muthén, 2015) in which positive contact, controlling for previous romantic outgroup relationships, was hypothesised to predict all four mediators (norms, anxiety, empathy, trust) which, in turn, predicted all three outcome variables (positive general attitude, dating, marriage). Variables on the same level (e.g., mediators) were allowed to covary, and direct paths from positive contact and previous outgroup romantic relationships to the mediators and outcome variables were modelled. Figure 1 shows the significant paths of the model, revealing that positive contact was significantly associated with a positive general outgroup attitude but not with likelihood of outgroup dating or appropriateness of outgroup marriage partner. Positive contact was also significantly and simultaneously associated with all proposed mediators in the expected directions (positively associated with norms, empathy, 
trust, and negatively associated with anxiety). All of these mediators were then significantly associated with a positive general outgroup attitude in the expected directions. Meanwhile, only norms were positively associated with likelihood of dating and perceived appropriateness of outgroup marriage partner. In addition, previous romantic relationships with outgroup members was directly associated with both relationship measures but was not associated with any other variables in the model.

To further examine the indirect effects of positive contact on the criteria variables (H1 and $\mathrm{H} 2$ ), we used10,000 bias-corrected bootstrap samples and 95\% confidence intervals (CIs: Muthén \& Muthén, 2015), whilst controlling for previous outgroup romantic relationships. Table 2 presents the standardised total effects, direct effects, and total indirect effects, along with the specific indirect effects, for each criterion variable. In support of $\mathrm{H} 1$, more positive general outgroup attitudes were directly predicted by positive contact and indirectly predicted through all the proposed mediators. This suggests that positive contact predicts lower prejudice and does so, in part, through greater trust, empathy, perceived norms, and lower anxiety.

Illustrating the importance of ingroup norms for entering into romantic relationships and providing support of $\mathrm{H} 2$, perceived ingroup dating norms was the only consistent mediator between positive contact and both outgroup relationship measures (dating and marriage). Notably, positive contact was not directly associated with likelihood of outgroup dating or perceived appropriateness of outgroup marriage partner in the model. Instead, the influence of intergroup contact on dating attitudes was explained by the mediational properties of ingroup dating norms and trust. Similarly, contact also predicted receptivity to more serious relationships (i.e., marriage) via the ingroup dating norm and reduced intergroup anxiety. This suggests that positive contact increases the potential for outgroup 
relationships (dating and marriage) because, in part, the contact improves the perceived acceptability of such relationships.

Together these findings suggest that whereas general outgroup attitudes in Northern Ireland are still readily explained by the traditional intergroup mechanisms (i.e., by contact via empathy, anxiety, trust, norms e.g., McKeown \& Taylor, 2018; Paolini et al., 2004; Tam et al., 2009; Turner et al., 2013), attitudes towards more intimate intergroup concerns (i.e., romantic relationships) are more likely to be impacted by normative concerns about dating than general outgroup feelings.

\section{Moderated-mediation analyses}

Using Mplus and amended syntax from Stride and colleagues (2015), we next tested whether the observed mediational pathways were moderated by participants' strength of identification with their religious community (H3). To limit decreases to statistical power, we ran separate models for each combination of mediator (4) and criterion (3) variables, resulting in 12 models that generated unstandardised estimates of the levels of the moderator from 1000 bootstrap samples and $95 \% \mathrm{CIs}^{1}$. Figure 2 shows the tested models which allowed us to investigate the conditional indirect effects, particularly whether the strength of ingroup identification moderated the relationship between contact and the mediators (a paths: H3). For exploratory purposes, we also tested for conditional direct effects (i.e., moderated c' paths between contact and the criterion variables). Whilst conducting these analyses, we controlled for previous outgroup romantic relationships.

Positive general outgroup attitude. As noted above (Figure 1, Table 2), contact was positively associated with a positive general outgroup attitude mediated by anxiety, empathy, norms, and threat, when controlling for previous outgroup romantic relationships. Lending some support to $\mathrm{H} 3$, the moderated-mediational analyses revealed that the mediational pathways of both anxiety and empathy were dependent upon the strength of group 
identification. Specifically, strength of group identification moderated the relationships between contact and intergroup anxiety $(\beta=-.11[-.17,-.05])$ and between contact and outgroup empathy $(\beta=.08[.02, .16])$. Moreover, conditional indirect effects showed that both anxiety and empathy were significant mediators between contact and outgroup attitude for those who were most highly identified with their group (as opposed to those more weakly identified with their group). For example, anxiety was a significant mediator for high identifiers $(\mathrm{B}=3.55[2.01,6.32])$ and moderate identifiers $(\mathrm{B}=2.20[1.12,4.15])$ but not for weakly identified group members $(B=0.84[-0.21,2.40])$, contrary to Tausch et al. (2007). This same pattern was observed for the mediational properties of empathy: empathy was a stronger mediator for high identifiers $(\mathrm{B}=2.20[0.88,4.32])$ and moderate identifiers $(\mathrm{B}=$ $1.61[0.62,3.17])$ than weak identifiers $(\mathrm{B}=1.03[0.24,2.36])$. This suggests that positive contact predicts a more positive general outgroup attitude because it predicts lower anxiety and greater empathy for the outgroup - but primarily for those who are more strongly identified with their ingroup. This, then, adds further support for understanding the differential impacts of intergroup contact for those who are most highly identified with their ingroup (e.g., Hodson et al., 2009).

Romantic relationship variables. Next, we tested the same potential moderating role of strength of group identification on the relationship measures (likelihood of outgroup dating or appropriateness of outgroup marriage partner). These eight moderated-mediational models revealed just one significant moderated-mediation: strength of group identification moderated the relationship between contact and empathy $(\beta=08[.02, .16])$ which resulted in significant conditional indirect effects on likelihood of outgroup dating. For those highly $(\mathrm{B}=.13[.01$, $.36])$ and moderately identified with their group $(\mathrm{B}=.09[.01, .27])$, the association between contact and positive attitudes towards dating was mediated by empathy, but not for those who were weakly identified with their group $(\mathrm{B}=.06[.00, .19])$. So, although empathy was not 
found to mediate the relationship between positive contact and dating in the larger model (Figure 1, Table 2), these findings suggest that empathy may, in fact, be an important mediator between these two constructs but only for those more highly identified with their group.

Conditional direct effects. Whereas the mediational pathways between contact and appropriateness of outgroup marriage partner were not found to be moderated by group identification, the direct relationship between contact and appropriateness of outgroup marriage partner was moderated $(\beta=.16[.03, .31])$, as was the direct association between contact and likelihood of outgroup dating $(\beta=.25,[.12, .39])$. For those moderately and highly identified with their group, contact was directly and positively associated with personal receptiveness for both types of outgroup relationships (all $\mathrm{Bs}>0.32$, all CIs did not straddle zero) but there were no such positive associations for those weakly identified with their group (weak identifiers and dating receptiveness: $\mathrm{B}=.01,[-.27, .24]$; weak identifiers and marriage partner appropriateness: $\mathrm{B}=.05[-.05, .23])$. There was, however, no significant interaction by group identification on the direct link between contact and a positive general outgroup attitude $(\mathrm{B}=0.78[-0.52,1.88])$. The finding of moderated direct effects for the romantic, but not general, outcome variables suggests the influence of unmodeled mediator(s) that are also moderated by identification ${ }^{2}$.

\section{Discussion}

The recent Brexit vote serves as a pertinent reminder of the politically and socially volatile context in Northern Ireland. It also highlights the need for intergroup contact theorists to continue investigating the efficacy and mechanisms by which intergroup contact can improve intergroup relations in a historically divisive context. In this study we continue a long tradition in showing that positive intergroup contact between Catholics and Protestants 
was associated with a positive general attitude towards the other community by predicting lower intergroup anxiety, greater empathy, more favourable ingroup norms about dating, and greater intergroup trust (McKeown \& Taylor, 2018; Paolini et al., 2004; Tam et al., 2009; Turner et al., 2013). Although all four factors have been identified as significant mediators previously, this is the first study to show that all four factors simultaneously play an important - and distinct - role in explaining the contact-bias relation.

We also extend the literature by demonstrating for the first time that positive intergroup contact in this context was significantly associated with a greater receptiveness to cross-group romantic relationships, primarily mediated by perceived ingroup dating norms. Furthermore, strength of group identification was found to directly moderate the relation between contact and receptiveness to outgroup romances, and conditional indirect effects were found for the association between contact and general attitude, with group identification moderating the mediational pathways of anxiety and empathy. Overall, these moderations suggest that intergroup contact may be more beneficial for those most highly identified with their group (Hodson et al., 2009).

The findings highlight the utility of examining different operationalisations of intergroup outcomes. Whereas previous research in Northern Ireland has generally conceptualised intergroup relations in terms of general attitudes or behavioural intentions towards the outgroup (e.g., Tausch et al., 2007), here we set the bar particularly high for the contact hypothesis, examining attitudes towards cross-group romantic relationships, where the "rubber hits the road" in pushing the potential of contact as a prejudice reduction process. In doing so, we found that positive intergroup contact is positively associated with receptiveness to cross-group romances, mirroring effects on general attitudes, a finding which leaves us optimistic about the potential for contact to improve intergroup relations, even in potentially volatile contexts (see also Lemmer \& Wagner, 2015). 
The mechanisms through which contact predicts these general versus romantic attitudes, however, are distinct. As hypothesised, positive contact predicted outgroup attitudes mediated by empathy, trust, anxiety, and norms. This was the first simultaneous test of these mediators, demonstrating that each mechanism is important even when controlling for the influence of one another. Nevertheless, the associations between contact and the romantic outcomes were primarily mediated by ingroup norms about cross-group dating (though trust also mediated the contact-dating relation and anxiety mediated the contact-marriage relation). This supports the interpersonal literature whereby support from important others, such as family and friends, is influential in entering into and maintaining romantic relationships (Uskul et al., 2007). It also supports the intergroup literature which shows that individuals use perceived opinions of ingroup members as referential information which influences their own outgroup attitudes (McKeown \& Taylor, 2018; Wright, Aron, Mclaughlin-Volpe, \& Ropp, 1997). By integrating these literatures, we show that ingroup norms are likely to play a key role in understanding how interpersonal relationships help individuals to cross group boundaries and even improve intergroup relations by blurring group definitions through marriage, and potentially, by having children with a mixed community background.

The moderated-mediational analyses also revealed some important differences in how contact is associated with general and romantic attitudes. For general attitudes, strength of group identification moderated the mediational pathways of anxiety and empathy (the $a$ paths) suggesting that, for high identifiers, contact improves general attitudes because it predicts lower anxiety and greater empathy. However, for romantic attitudes, group identification moderated the direct link between contact and the attitudes (the $c$ paths), again suggesting that contact increases receptiveness to romantic relationships but only for the high identifiers. Despite the difference in where the moderation has an effect, what is noticeable is that contact seems to have a more beneficial effect on those most identified with their group 
for both general and romantic attitudes. Such a finding suggests that those most concerned with their group are more affected by intergroup matters and so, optimistically, those who are most identified and prejudiced may also be most positively affected by intergroup contact (Hodson, 2011).

Notable, too, is the role of previous romantic outgroup contact. Whilst the focus of the current study was to investigate how positive general contact influences general and romantic cross-group attitudes, the use of previous romantic outgroup contact as a covariate is informative. First, it shows that general (non-romantic) contact promotes positive intergroup attitudes above and beyond those that may be associated with romantic intergroup contact. Second, our results show that, while Northern Ireland may be considered a relatively positive intergroup context compared to currently warring contexts, the context remains relatively romantically segregated with $70 \%$ of the sample indicating that they had never been in a relationship with an outgroup member (see also Leonard, 2009). Third, the results show that although romantic attitudes may be a litmus test of intergroup relations, actually being in a cross-group romantic relationship does not necessarily translate into positive attitudes.

Although we draw on previous research to hypothesise that the disapproval of others may dull initial positive attitudes (e.g., Paterson et al., 2015; Uskul et al., 2007), further research would be helpful in addressing why involvement in cross-group romantic relationships does not generalise to positive intergroup attitudes in similar ways to more general (non-romantic) positive contact.

As with any cross-sectional data, we cannot determine causal direction and any mediational analyses would be best supported by longitudinal data. In addition, further replications of the study would benefit from larger samples and, thus, greater statistical power to test the generalisability of the current findings. However, an extensive body of experimental, longitudinal and cross-sectional literature supports our hypothesis that contact 
promotes more positive attitudes (e.g., Brown, Eller, Leeds, \& Stace, 2007; Pettigrew \& Tropp, 2006). Another potential limitation involves the measurements used. For example, the item used to measure norms was specifically related to cross-group romantic relationships whereas the other three mediators were more general. In addition, only one item measured each of the criterion variables. Relatedly, the wording of the dating and marriage variables differed from each other (i.e., referring to likelihood vs. appropriateness), and so although we argue that any differences between these measures are a result of the closeness of these types of relationships, it is possible that any differences are, in fact, a consequence of the different wording used to measure these variables. The finding that the direct (i.e., unmediated) effect of positive contact on the relationship criteria is moderated by identification could reflect lower reliability on these measures or might suggest the presence of unaccounted mediator(s) in the model that is also influenced by identification. Further examination of other potential mediators specific to understanding the relation between contact and romantic relationships would be helpful, for example, contact with the outgroup may increase familiarity with outgroup members, and since familiarity is associated with attraction (Halberstadt, Rhodes, \& Catty, 2003), this factor may also help explain why contact increases receptiveness to outgroup romances.

Our reliance on student participants may also limit the conclusions we draw from this research. Although only participants who identified as Catholic and Protestant were used, the fact that they were recruited from a relatively desegregated context in Belfast (University) may indicate that they already held favourable attitudes (e.g., the mean outgroup thermometer rating was 78.22 out of 100) and may not be representative of their respective communities. Furthermore, because participants were relatively young $(M=21$ years old $)$, attitudes towards cross-group romantic relationships may be more favourable than attitudes towards people who personally lived through the 'Troubles'. 
Nevertheless, while the findings from this sample may not generalise to individuals who have lived, or are currently living, in more hostile and divisive environments, the fact that this sample hold relatively positive attitudes, and that contact predicts such attitudes, is encouraging. In just 20 years since the Good Friday Peace Agreement was signed, divisions between communities, although still wrought with difficulties, have lessened to such a degree that group members not only hold somewhat favourable outgroup attitudes, they will even consider dating outgroup members (though such relationships are still relatively uncommon, see Table 1). This implies that intergroup contact can produce positive intergroup benefits, even in previously warring contexts in a relatively short space of time. The findings, therefore, should continue to motivate the application of intergroup contact theory as well as inspiring further investigation into the many diverse benefits that can result from it, including more positive intergroup romantic attitudes. To further contribute to the literature, these future applications and studies should use more representative community samples and more precise measurement tools. In the Northern Irish context, meanwhile, longitudinal studies would be well placed to explore the impact of Brexit and the potential implementation of a hard or soft border between Northern Ireland and the Republic of Ireland on community relations.

\section{Concluding Remarks}

Contact researchers have long been drawn to the sectarian tensions present in the Northern Ireland context, and recent political turmoil and uncertainty necessitates further scrutiny. The present study goes beyond previous research and highlights the need to examine different operationalisations of intergroup outcomes, in particular, attitudes towards crossgroup romantic relationships as these may provide a more nuanced picture of intergroup relations. Furthermore, this study highlights the importance of norms, not only in predicting 
general attitudes toward outgroups but also in individuals' willingness to engage in romantic relationships with outgroup members. Lastly, the study supports previous research indicating that the effects of contact are stronger for individuals who most identify with their group (Hodson et al., 2009). These findings are important because they not only expand upon previous research, but also serve as a reminder that although the conflict in Northern Ireland may have abated, it remains a powder keg situation - but a situation in which social psychology can be used to help better understand and prevent any possible escalations of the current tensions. 
1. The syntax provided by Stride et al. (2015) provides standardised coefficients for the moderation analyses but unstandardized coefficients for the levels of the moderator. As such, we report the standardised betas for the moderation values and illustrate the levels of identity using unstandardized coefficients.

2. In addition to the statistically significant findings noted above, strength of group identification marginally moderated the relationship between contact and ingroup norms $(\beta=$ $.16[-.01, .29], p=.052)$. The conditional indirect effects suggest that ingroup dating norms are likely to be a significant mediator between contact and all three criterion variables for those moderately and highly identified with their group (all $\beta \mathrm{s}>.22$, all CIs exclude zero), but not for those weakly identified with their group (all $\beta \mathrm{s}<.37$, all CIs include zero). Nevertheless, as the initial moderation between contact and ingroup norms was marginally significant, such results should be treated with caution. 
Table 1

Descriptive statistics and correlations between variables

\begin{tabular}{|c|c|c|c|c|c|c|c|c|c|c|c|}
\hline & Scale & $M(\mathrm{SD})$ & 1 & 2 & 3 & 4 & 5 & 6 & 7 & 8 & 9 \\
\hline 1. Positive contact & $1-7$ & $\begin{array}{c}5.33 \\
(1.32)\end{array}$ & - & & & & & & & & \\
\hline $\begin{array}{l}\text { 2. Previous outgroup } \\
\text { romantic relationships }\end{array}$ & $1-5$ & $\begin{array}{c}1.53 \\
(0.90)\end{array}$ & $.31 * * *$ & - & & & & & & & \\
\hline 3. Ingroup dating norms & $1-9$ & $\begin{array}{c}6.68 \\
(2.02)\end{array}$ & $.32 * * *$ & .09 & - & & & & & & \\
\hline 4. Intergroup anxiety & $1-7$ & $\begin{array}{c}1.94 \\
(1.06)\end{array}$ & $-.40 * * *$ & $-.16^{*}$ & $-.27 * * *$ & - & & & & & \\
\hline 5. Outgroup empathy & $1-7$ & $\begin{array}{c}4.67 \\
(1.33)\end{array}$ & $.43 * * *$ & .15 & $.25^{* *}$ & $-.35 * * *$ & - & & & & \\
\hline 6. Outgroup trust & $1-7$ & $\begin{array}{c}4.78 \\
(1.24)\end{array}$ & $.22 * *$ & .02 & $.22 * *$ & $-.32 * * *$ & $.31 * * *$ & - & & & \\
\hline 7. Group identification & $1-7$ & $\begin{array}{c}3.68 \\
(1.73)\end{array}$ & -.15 & -.15 & $-.23 * *$ & $.24 * *$ & -.15 & $-.30 * * *$ & - & & \\
\hline $\begin{array}{l}\text { 8. Likelihood of outgroup } \\
\text { dating }\end{array}$ & $1-9$ & $\begin{array}{c}7.41 \\
(2.29)\end{array}$ & $.42 * * *$ & $.20 * *$ & $.58 * * *$ & $-.40 * * *$ & $.34 * * *$ & $.26^{* *}$ & $-.37 * * *$ & - & \\
\hline $\begin{array}{l}\text { 9. Appropriateness of own } \\
\text { outgroup marriage }\end{array}$ & $1-9$ & $\begin{array}{c}7.23 \\
(2.13)\end{array}$ & $.32 * * *$ & $.33 * * *$ & $.58 * * *$ & $-.28 * * *$ & $.27 * *$ & $.29 * * *$ & $-.40 * * *$ & $.83 * * *$ & - \\
\hline
\end{tabular}




\begin{tabular}{|c|c|c|c|c|c|c|c|c|c|c|c|}
\hline 10. Positive general & $0-$ & 78.22 & $.48 * * *$ & $.19 *$ & $.39 * * *$ & $-.56 * * *$ & $.46^{* * *}$ & $.47 * * *$ & $-.27 * *$ & $.41 * * *$ & $.42 * * *$ \\
\hline outgroup attitude & 100 & $(19.27)$ & & & & & & & & & \\
\hline
\end{tabular}

$* * * p<.001, * * p<.01$. 
Figure 1

Tests of hypothesised mediation model, controlling for previous outgroup romantic relationships

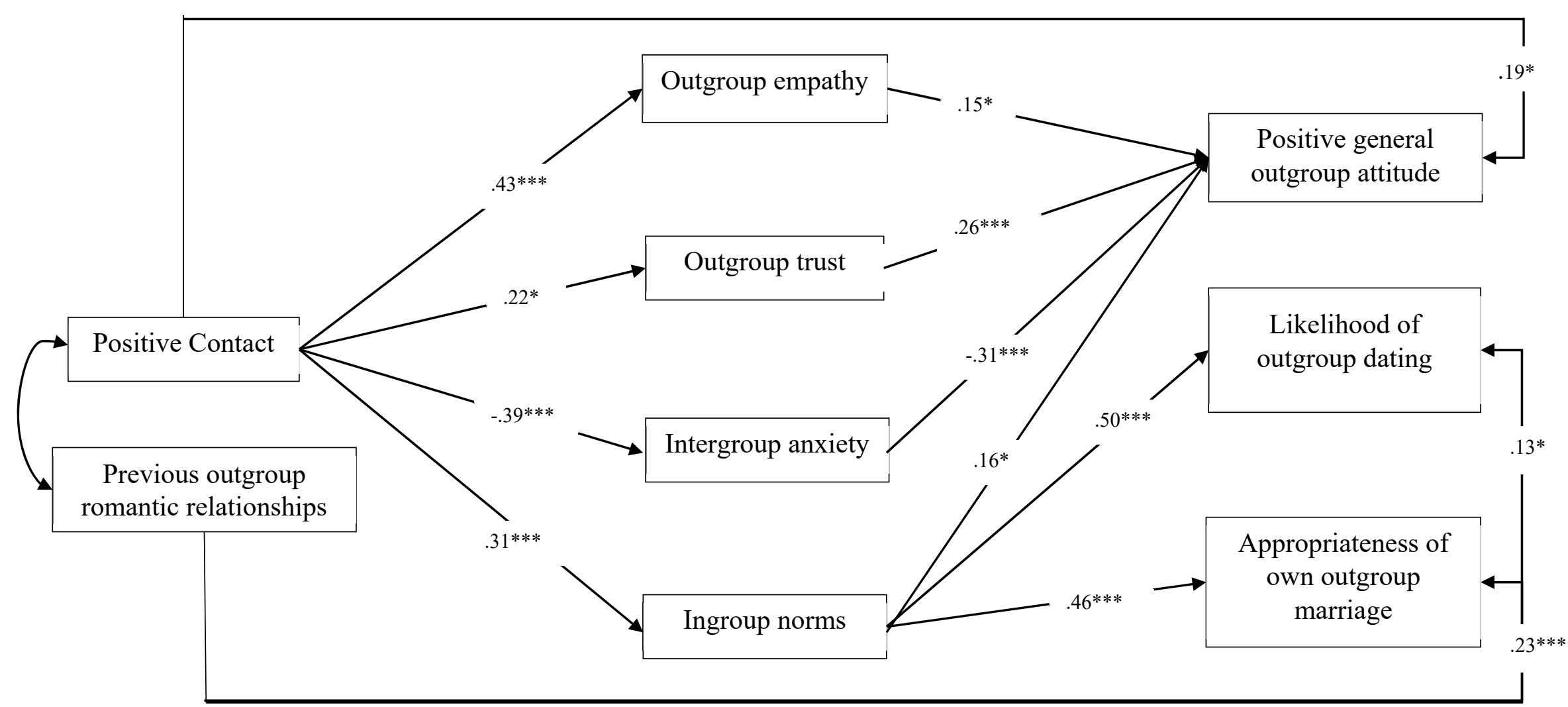

Note. All paths are standardised. All paths were modelled but non-significant paths are not shown for brevity; ${ }^{*} p<.05, * * p<.01$, $* * * p<.001$. 
Table 2

Standardized total, direct and significant indirect effects of positive contact (mediation analyses)

\begin{tabular}{|c|c|c|c|c|}
\hline Criterion & Total effect & Direct effect & $\begin{array}{l}\text { Total indirect } \\
\text { effect }\end{array}$ & Specific indirect effects \\
\hline $\begin{array}{l}\text { Positive general } \\
\text { outgroup attitude }\end{array}$ & $.46 *[.28, .59]$ & $.17 *[.03, .32]$ & $.29 *[.17, .41]$ & $\begin{array}{l}\text { Norms: } .05 *[.01, .12] \\
\text { Anxiety: } .12 *[.05, .21] \\
\text { Empathy: .06*[.004,.14] } \\
\text { Trust: .06*[.02,.13] }\end{array}$ \\
\hline $\begin{array}{l}\text { Likelihood of } \\
\text { outgroup dating }\end{array}$ & $.28 *[.11, .43]$ & $.07[-.08, .23]$ & $.23 *[.10, .36]$ & $\begin{array}{l}\text { Norms: .16*[.08,.25] } \\
\text { Anxiety .02[-.04,.10] } \\
\text { Empathy: .02[-.03,.08] } \\
\text { Trust: .03* }[.001, .09]\end{array}$ \\
\hline $\begin{array}{l}\text { Appropriateness } \\
\text { of own outgroup } \\
\text { marriage }\end{array}$ & $.34 *[.18, .48]$ & $.10[-.05, .24]$ & $.25 *[.13, .37]$ & $\begin{array}{l}\text { Norms: .15*[.08,.23] } \\
\text { Anxiety: .06*[.003,.15] } \\
\text { Empathy: .03[-.02,.09] } \\
\text { Trust: .02[-.01, .06] }\end{array}$ \\
\hline
\end{tabular}

Note. $95 \%$ bias-corrected confidence intervals of the standardised estimate are presented in brackets. Statistical significance $(p<.05)$ is denoted with * and inferred if the intervals do not include zero. Previous romantic outgroup relationships were included as a covariate. 
Figure 2

Conceptual illustration of moderated-mediation models

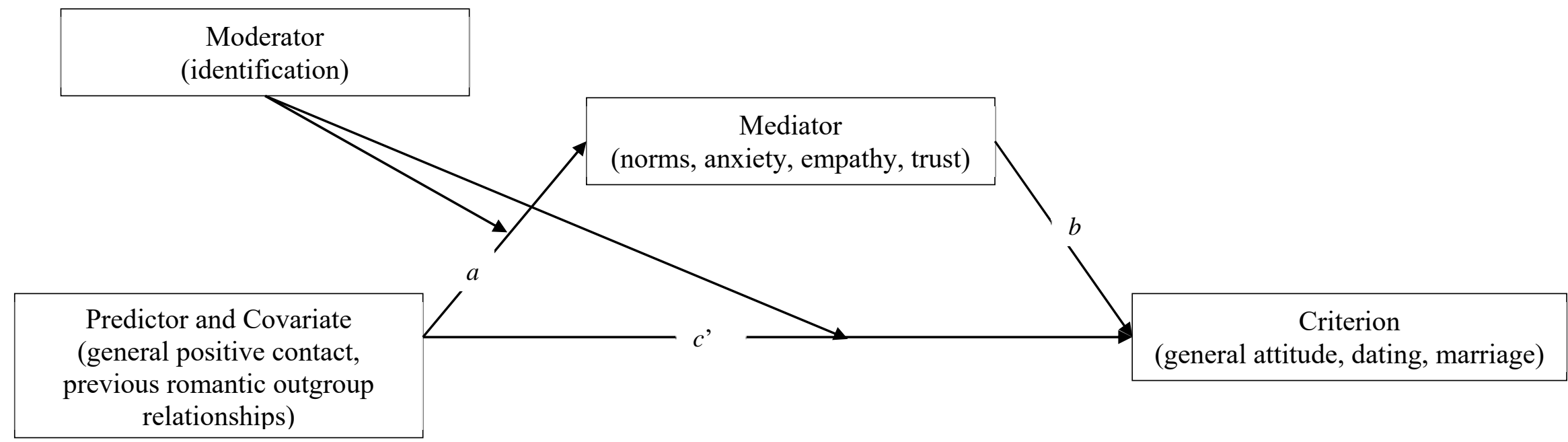

Note. Separate models were run for each mediator-criterion combination, resulting in 12 models (i.e., 4 mediators $\mathrm{x} 3$ criteria). Contact was always the predictor, previous romantic outgroup relationships was always the covariate, identification was always the moderator, and the moderation of the a and c' paths were tested simultaneously in each of the models. 


\section{References}

Allport, G. W. (1954). The nature of prejudice: Addison-Wesley.

Ata, A., Bastian, B., \& Lusher, D. (2009). Intergroup contact in context: The mediating role of social norms and group-based perceptions on the contact-prejudice link. International Journal of Intercultural Relations, 33(6), 498-506.

Batson, C. D., Polycarpou, M. P., Harmond-Jones, E., Imhoff, H. J., Mitchener, E. C., Bednar, L. L., .. . Highberger, L. (1997). Empathy and attitudes: Can feeling for a member of a group improve feelings towards the group? Journal of Personality and Social Psychology, 72(1), 105-118.

Bogardus, E. S. (1967). A forty year racial distance study: University of Southern California.

Brown, R., Eller, A., Leeds, S., \& Stace, K. (2007). Intergroup contact, perceived typicality and intergroup attitudes: a longitudinal study. European Journal of Social Psychology, 37, 692-703.

Cramer, D., \& Jowett, S. (2010). Perceived empathy, accurate empathy and relationship satisfaction in heterosexual couples. Journal of Social and Personal Relationships, 27(3), 327-349.

Fang, C. Y., Sidanius, J., \& Pratto, F. (1998). Romance across the social status continuum: Interracial marriage and the ideological asymmetry effect. Journal of Cross-Cultural Psychology, 29(2), 290-305.

Gormley-Heenan, C., \& Aughey, A. (2017). Northern Ireland and Brexit: Three effects on 'the border in the mind'. The British Journal of Politics and International Relations, 19(3), 497-511.

Haddock, G., Zanna, M. P., \& Esses, V. M. (1993). Assessing the structure of prejudicial attitudes: The case of attitudes toward homosexuals. Journal of Personality and Social Psychology, 65, 1105-1118. 
Halberstadt, J., Rhodes, G., \& Catty, S. R. (2003). Subjective and objective familiarity as explanations for the attraction to average faces. Advances in psychology research, 22, $35-49$.

Hewstone, M., \& Hughes, J. (2015). Reconciliation in Northern Ireland: The value of intergroup contact. BJPsych international, 12(3), 65-67.

Hodson, G. (2011). Do ideologically intolerant people benefit from intergroup contact? Current Directions in Psychological Science, 20(3), 154-159.

Hodson, G., Harry, H., \& Mitchell, A. (2009). Independent benefits of contact and friendship on attitudes toward homosexuals among authoritarians and highly identified heterosexuals. European Journal of Social Psychology, 39(4), 509-525.

Joyner, K., \& Kao, G. (2005). Interracial relationships and the transition to adulthood. American Sociological Review, 70(4), 563-581.

Kalmijn, M. (1998). Intermarriage and homogamy: Causes, patterns, trends. Annual review of sociology, 24(1), 395-421.

Kteily, N. S., Hodson, G., Dhont, K., \& Ho, A. K. (2019). Predisposed to prejudice but responsive to intergroup contact? Testing the unique benefits of intergroup contact across different types of individual differences. Group Processes \& Intergroup Relations, 22(1), 3-25. doi:10.1177/1368430217716750

Lalonde, R. N., Giguère, B., Fontaine, M., \& Smith, A. (2007). Social dominance orientation and ideological asymmetry in relation to interracial dating and transracial adoption in Canada. Journal of Cross-Cultural Psychology, 38(5), 559-572.

Lemmer, G., \& Wagner, U. (2015). Can we really reduce ethnic prejudice outside the lab? A meta-analysis of direct and indirect contact interventions. European Journal of Social Psychology, 45, 152-168. doi:10.1002/ejsp.2079 
Leonard, M. (2009). 'It's better to stick to your own kind': teenagers' views on crosscommunity marriages in Northern Ireland. Journal of Ethnic and Migration Studies, 35(1), 97-113.

Levin, S., \& Sidanius, J. (1999). Social dominance and social identity in the United States and Israel: Ingroup favoritism or outgroup derogation? Political Psychology, 20(1), 99-126.

Levin, S., Taylor, P. L., \& Caudle, E. (2007). Interethnic and interracial dating in college: A longitudinal study. Journal of Social and Personal Relationships, 24(3), 323-341.

Lloyd, K., \& Robinson, G. (2011). Intimate mixing-bridging the gap? Catholic-Protestant relationships in Northern Ireland. Ethnic and Racial Studies, 34(12), 2134-2152.

MacInnis, C. C., \& Hodson, G. (2013). Expecting racial outgroups to view "us" as biased: A social projection explanation of Whites' bias meta-stereotypes. Group Processes \& Intergroup Relations, 16(5), 545-559.

McKeown, S., \& Taylor, L. K. (2018). Perceived peer and school norm effects on youth antisocial and prosocial behaviours through intergroup contact in Northern Ireland. British Journal of Social Psychology.

Miller, N. (2002). Personalization and the promise of contact theory. Journal of Social Issues, $58,387-410$.

Muthén, L. K., \& Muthén, B. (2015). Mplus. The comprehensive modelling program for applied researchers: user's guide, 5 .

Paolini, S., Hewstone, M., Cairns, E., \& Voci, A. (2004). Effects of direct and indirect crossgroup friendships on judgments of Catholics and Protestants in Northern Ireland: The mediating role of an anxiety-reduction mechanism. Personality and Social Psychology Bulletin, 30, 770-786. 
Paterson, J. L., Turner, R. N., \& Conner, M. T. (2015). Extended contact through cross-group romantic relationships. Journal of Applied Social Psychology, 45(9), 489-497.

Pettigrew, T. F. (1998). Intergroup Contact Theory. Annual Review of Psychology, 49, 65-85.

Pettigrew, T. F., \& Tropp, L. (2006). A meta-analytic test of intergroup contact theory. Journal of Personality and Social Psychology, 90, 751-783.

Plant, E. A., \& Devine, P. G. (2003). The antecedents and implications of interracial anxiety. Personality and Social Psychology Bulletin, 29(6), 790-801.

Rempel, J. K., Holmes, J. G., \& Zanna, M. P. (1985). Trust in close relationships. Journal of Personality and Social Psychology, 49(1), 95-112.

Sprecher, S., \& Felmlee, D. (1992). The influence of parents and friends on the quality and stability of romantic relationships: A three-wave longitudinal investigation. Journal of Marriage and the Family, 54(4), 888-900.

Stephan, W. G., \& Stephan, C. W. (1985). Intergroup anxiety. Journal of Social Issues, 41, 157-175.

Stride, C. B., Gardner, S., Catley, N., \& Thomas, F. (2015). Mplus code for the mediation, moderation, and moderated mediation model templates from Andrew Hayes' PROCESS analysis examples. Retrieved from http://www.figureitout.org.uk

Tajfel, H. (1970). Experiments in intergroup discrimination. Scientific American, 223(5), 96103.

Tam, T., Hewstone, M., Kenworthy, J., \& Cairns, E. (2009). Intergroup trust in Northern Ireland. Personality and Social Psychology Bulletin, 35(1), 45-59.

Tausch, N., Tam, T., Hewstone, M., Kenworthy, J., \& Cairns, E. (2007). Individual-level and group-level mediators of contact effects in Northern Ireland: The moderating role of social identification. British Journal of Social Psychology, 46(3), 541-556. 
Turner, R., Hewstone, M., Voci, A., \& Vonofakou, C. (2008). A test of the extended intergroup contact hypothesis: the mediating role of intergroup anxiety, perceived ingroup and outgroup norms, and inclusion of the outgroup in the self. Journal of Personality and Social Psychology, 95, 843-860.

Turner, R., Tam, T., Hewstone, M., Kenworthy, J., \& Cairns, E. (2013). Contact between Catholic and Protestant schoolchildren in Northern Ireland. Journal of Applied Social Psychology, 43, 216-228. doi:10.1111/jasp.12018

Uskul, A. K., Lalonde, R. N., \& Cheng, L. (2007). Views on interracial dating among Chinese and European Canadians: The roles of culture, gender, and mainstream cultural identity. Journal of Social and Personal Relationships, 24(6), 891-911.

Williams, M. J., \& Eberhardt, J. L. (2008). Biological conceptions of race and the motivation to cross racial boundaries. Journal of Personality and Social Psychology, 94(6), $1033-$ 1047

Wright, S. C., Aron, A., Mclaughlin-Volpe, T., \& Ropp, S. A. (1997). The extended contact effect: knowledge of cross-group friendships and prejudice. Journal of Personality and Social Psychology, 73, 73-90. 